\title{
Experimental and numerical study of the vertical motions of a bulk carrier and a Ro-Ro ship in extreme waves
}

\author{
Guillermo Vásquez $^{1}$ - Nuno Fonseca ${ }^{1}$ - C. Guedes Soares ${ }^{1}$
}

Received: 14 July 2014 / Accepted: 10 March 2015 / Published online: 11 April 2015

(c) Springer International Publishing AG 2015

\begin{abstract}
This paper investigates the experimental and numerical vertical motion responses of a bulk carrier and a Roll-on/Roll-off ship in extreme seas. The experimental data were obtained from seakeeping tests with scaled models in head waves at two Froude numbers. The wave traces were predefined, corresponding to wave records measured during storms in the North Sea. These wave records are particularly interesting because each of them include one abnormal wave. The ship models, which are similar in length but different in their geometry, were tested in the same predefined wave conditions to investigate the influence of the hull geometry on the extreme vertical ship responses. Conclusions are derived by comparing directly the measured responses from the two models. Experimental data are also used as benchmark to validate the predictions by a partially nonlinear time domain seakeeping numerical model. The numerical model code is then used to generalize the comparative analysis between the two ships.
\end{abstract}

Keywords Ship motions - Extreme waves - Nonlinear motions $\cdot$ Bulk carrier $\cdot$ Ro-Ro $\cdot$ Model tests

\section{Introduction}

Seakeeping in abnormal wave conditions have become more important during the last years, because some recent incidents proved that these extreme seas strongly threaten the safety and proper operation of the ship. Some reports from

\footnotetext{
C. Guedes Soares

c.guedes.soares@centec.tecnico.ulisboa.pt

1 Centre for Marine Technology and Ocean Engineering (CENTEC), Instituto Superior Técnico, Universidade de Lisboa, Av. Rovisco País, 1049-001 Lisbon, Portugal
}

cruise vessels encountering rogue waves, such as Grand Voyager (February 2005) (Bertotti and Cavaleri 2008), Norwegian Dawn (April 2005) (Didenkulova et al. 2006) and MS Louis Majesty (March 2010) (Cavaleri et al. 2012), confirm that ships might be exposed to extreme environment conditions during its lifetime, including encounters with abnormal waves, whose damaging effects have already been pointed out by Faulkner and Buckley (1997). These extreme waves induce large dynamic ship responses with associated nonlinear effects, therefore, the seakeeping numerical model tools to analyse the problem have to consider the relevant nonlinear effects. Examples of nonlinear effects are those related to the large amplitude oscillation of the boundaries (ship hull and free surface), non-vertical sides of the hull and large amplitude kinematics of the fluid (among others). Nonlinear solutions for the seakeeping problem are almost exclusively obtained in the time domain. The final seakeeping report and recommendations of the 26th International Towing Tank Conference (ITTC-2011) mentions that presently two methods seem to take a lead in terms of practical applications of seakeeping time domain calculation. Those are the strip-based time domain and Rankine panel methods.

The numerical results presented are based on the partial nonlinear numerical method developed by Fonseca and Guedes Soares (1998a,b) to predict the vertical ship responses in large amplitude waves. The method is based on a time domain solution where hydrostatic and Froude-Krylov forces are nonlinear and computed over the instantaneous hull wetted surface, while radiation and diffraction forces are kept linear. The radiation forces are represented by the convolution of memory functions, infinite frequency added masses and radiation restoring coefficients. The validation of this method has been done over several years by systematic comparison with model test experimental data (Fonseca 
and Guedes Soares 2002, 2004a, b, 2005). In the last contributions, Guedes Soares et al. (2006) and Fonseca et al. (2010) studied the vertical response of an FPSO operating in North Sea, with emphasis on the response induced by extreme seas. They concluded that in general the numerical model represents all nonlinear effects detected on the experimental results and the prediction of heave and pitch is in good agreement with experiments. Rajendran et al. (2011) investigated the seakeeping of a modern container ship advancing in head sea for four Froude numbers ( $F n=0,0.06,0.12$ and 0.18 ) in predefined wave traces including abnormal waves. Comparisons in the time domain show that the calculated motion responses compare well with the model test results, with only a slight deviation in heave and pitch responses when the abnormal wave encounters the ship. The predictions of this code were also compared with other codes of similar type of approximations showing consistent predictions (Watanabe and Guedes Soares 1999).

It is necessary to note that nonlinearities may come from the hull geometry, the sea state or a combination of both. The nonlinear response is then the combined effect of the nonlinearities induced by the hull geometry or the sea state and the question is: for the same extreme sea state condition, how much is the influence of the hull geometry on the response?

The nonlinear geometry hull effects over the ship behaviour have been investigated experimentally. Watanabe et al. (1989) analysed the effects of bow flare shape on the motions and loads on a container ship. The hull model was the S175 , which was prepared to accommodate an additional bow flare so one can easily obtain another model with increased flare but with the same underwater profile and dynamic characteristics. It was concluded that increased bow flare form reduces relative bow motion and serious deck wetness, increases the vertical bending moment and may deform the incoming wave profile considerably. Fonseca and Guedes Soares (2004c) investigated the nonlinear characteristics of the vertical responses of the same ship advancing in regular wave with several wave steepnesses (representing small to large amplitude waves) and showed that the nondimensional resonance amplitudes of the heave and pitch decrease when the wave steepness increases. For frequencies away from the resonance frequency, the nondimensional amplitudes could be considered independent of the wave steepness.

Adegeest (1995) presented experimental results for two Wigley hulls, the original and a modified one. The original Wigley hull has the characteristic that the sides are vertical around the still waterline all along the length, whereas the second hull has a modified bow with significant flare. The author shows that some differences occur between the first harmonic heave motions of the two models in the resonance peak and differences between the first harmonic pitch are negligible. Clauss et al. (2010) presented a study of the influence of the bow shape on the wave-induced loads in high and steep waves for two different ships, the Ro-on/Rooff (Ro-Ro) vessel with its V-shaped frame design and the bulk carrier with its full bow. The wave heights and related steepness have been selected to obtain wave profiles with different crest/trough asymmetries to cover waves in the linear range, Stokes II waves and Stokes III waves. Results from this analysis show that the Ro-Ro vertical bending moment is characterized by important nonlinear effects, especially for steeper waves, whilst the bulk carrier does not show significant nonlinear characteristics.

The review of previous investigations seems to indicate that the nonlinear behaviour of the wave-induced vertical ship responses are very much related to the ship's hull geometry-nonlinear effects are relatively small for large block coefficient ships and they are significant for small block coefficient ships. The objective of the present study is to present experimental evidence of the hull geometry influence on the vertical ship motions induced by extreme waves and systematically compare the linear and nonlinear response effects for two ships with different block coefficients. The two ships are a bulk carrier and a Roll-on/Roll-off ship (RoRo) and their block coefficients are, respectively, 0.82 and 0.71 . Scaled models were tested in a seakeeping basin under the same irregular waves (same wave traces), under head sea condition and several Froude numbers.

The experimental wave traces were predefined and correspond to wave records measured during storms in the North Sea. They include abnormal waves, which are individual waves with height larger than two times the sea state significant wave height, which is the generally accepted definition (Clauss 2002; Guedes Soares et al. 2003; Kharif and Pelinovsky 2003). Partial conclusions are derived by comparing the measured responses from the two models. But experimental data are also used to validate the predictions by a partially nonlinear time domain seakeeping numerical model. The code is then used to generalize the comparative analysis between the two ships for a wide range of regular wave conditions.

\section{Calculation method}

The seakeeping calculations of the following section are carried with a time domain seakeeping numerical model based on the formulation proposed by Fonseca and Guedes Soares (1998a,b). The method assumes that the nonlinear contribution for the vertical responses is dominated by hydrostatic and Froude-Krylov forces, thus these components depend on the instantaneous hull wetted surface. The exciting forces due to the incident waves are decomposed into diffraction part and Froude-Krylov part. The diffraction part, which is 
related to the scattering of the incident wave field due to the presence of the non-moving ship, is kept linear. Since this is a linear problem and the exciting waves are known a priori, it can be solved in the frequency domain and the resulting transfer functions can be used to generate a time history of the diffraction heave force and pitch moment. The FroudeKrylov force is related to the incident wave potential and results from the integration at each time step of the associated pressure over the wetted surface of the hull under the undisturbed wave profile.

The radiation forces are represented in the time domain by infinite frequency added masses, radiation restoring coefficients and convolution integrals of memory functions. The convolution integrals represent the effects of the whole past history of the motion accounting for the memory effects due to the radiated waves. Both the radiation and diffraction coefficients in the frequency domain are calculated by a strip method. The vertical forces associated with the green water on deck, which occurs when the relative motion is larger than the freeboard, are calculated using the momentum method (Buchner 1995). This seakeeping numerical model is based on a "partially nonlinear method". This means that the equations of motions and loads combine linear and nonlinear terms.

The heave and pitch equations of motion in the time domain are:

$$
\begin{aligned}
& \left(M+A_{33}^{\infty}\right) \ddot{\xi}_{3}(t)+\int_{-\infty}^{t}\left[K_{33}^{m}(t-\tau) \dot{\xi}_{3}(\tau)\right] \mathrm{d} \tau+C_{33}^{m} \xi_{3}(t) \\
& +A_{35}^{\infty} \ddot{\xi}_{5}(t)+\int_{-\infty}^{t}\left[K_{35}^{m}(t-\tau) \dot{\xi}_{5}(\tau)\right] \mathrm{d} \tau+C_{35}^{m} \xi_{5}(t) \\
& +F_{3}^{H}(t)-M g+F_{3}^{g w}(t)=F_{3}^{D}(t)+F_{3}^{K}(t) \\
& \left(I_{55}+A_{55}^{\infty}\right) \ddot{\xi}_{5}(t)+\int_{-\infty}^{t}\left[K_{55}^{m}(t-\tau) \dot{\xi}_{5}(\tau)\right] \mathrm{d} \tau+C_{55}^{m} \xi_{5}(t) \\
& +A_{53}^{\infty} \ddot{\xi}_{3}(t)+\int_{-\infty}^{t}\left[K_{53}^{m}(t-\tau) \dot{\xi}_{3}(\tau)\right] \mathrm{d} \tau+C_{53}^{m} \xi_{3}(t) \\
& +F_{5}^{H}(t)+F_{5}^{g w}(t)=F_{5}^{D}(t)+F_{5}^{K}(t)
\end{aligned}
$$

where $\xi_{3}$ and $\xi_{5}$ represent, respectively, the heave and pitch motions and the dots over the symbols represent differentiation with respect to time. $M$ is the ship mass; $g$ is the acceleration of gravity and $I_{55}$ represents the ship inertia about the $y$-axis.

The hydrostatic force and moment, $F_{3}^{H}$ and $F_{5}^{H}$, are calculated at each time step by integration of the hydrostatic pressure over the wetted hull under the undisturbed wave profile, as well as the Froude-Krylov contribution of the exciting forces $F_{k}^{K}$. The diffraction forces are represented by $F_{k}^{D}$.

The radiation force are represented in the time domain by infinite frequency added masses $A_{k j}^{\infty}$, radiation restoring coefficients $C_{k j}^{m}$, and convolution integrals of memory functions $K_{k j}^{m}(t)$. The radiation restoring forces, associated with the restoring coefficients, represent a correction to the hydrodynamic steady forces acting on the ship due to the steady flow. The memory functions and the radiation restoring coefficients are obtained by relating the radiation forces in the time domain and in the frequency domain by means of Fourier analysis:

$$
\begin{aligned}
& K_{k j}^{m}(t)=\frac{2}{\pi} \int_{0}^{\infty}\left\{B_{k j}(\omega) \cos \omega t\right\} \mathrm{d} \omega \\
& C_{k j}^{m}(t)=\omega^{2}\left[A_{k j}^{\infty}-A_{k j}(\omega)\right]-\omega \int_{0}^{\infty} K_{k j}^{m}(\tau) \sin (\omega \tau) \mathrm{d} \tau
\end{aligned}
$$

where $A_{k j}(\omega)$ and $B_{k j}(\omega)$ are the frequency-dependent added mass and damping coefficients calculated with a strip theory method proposed by Salvesen et al. (1970).

Finally, the vertical forces associated with the green water on deck, $F_{k}^{g w}(t)$, which occur when the relative motion is larger than the freeboard, are calculated using the momentum method:

$$
\begin{aligned}
& f^{g w}(x, t)=\left(\frac{\partial m_{g w}}{\mathrm{~d} t}\right) w+\left(g \cos \xi_{5}+\frac{\partial w}{\partial t}\right) m_{g w} \\
& F_{3}^{g w}(t)=\int_{L} f^{g w}(x, t) \mathrm{d} x \\
& F_{5}^{g w}(t)=\int_{L} x f^{g w}(x, t) \mathrm{d} x
\end{aligned}
$$

where $f^{g w}$ represents the vertical force per unit area, $w$ is the vertical velocity of the deck and $m_{g w}$ represents the mass of water on the deck per unit length. The hydrodynamic pressure on the deck includes three terms: the hydrostatic pressure, one term that accounts for the time variation of mass of water on the deck and one term associated with the acceleration of the deck. The height of water on deck is given by the difference between the relative motion at the bow and the freeboard, where the relative motion depends on the undisturbed free surface elevation. The mass of water on the deck is proportional to the height of water on the deck.

Comprehensive comparisons between experimental data and numerical results for a containership advancing in regular and irregular waves (Fonseca and Guedes Soares 2004b, c) have shown that the seakeeping numerical method used here is able to represent qualitatively all the nonlinear effects 
identified in the experimental data and is an improvement compared to the linear solution.

\section{Experimental program}

\subsection{Experimental setup}

The model tests were conducted in the seakeeping basin of the Ocean Engineering Division of the Technical University of Berlin at the model scale of 1:70 for both the bulk carrier and Ro-Ro ships. The basin is 110-m long, with a measuring range of $90 \mathrm{~m}$, the width is $8 \mathrm{~m}$ and the water depth is $1 \mathrm{~m}$. On one side an electrically driven piston type wave generator is installed. The wave generator is fully computer controlled and a software is implemented which enables the generation of transient wave packages, deterministic irregular sea states with predefined characteristics as well as tailor-made critical wave sequences (Clauss and Kühnlein 1996; Clauss and Schmittner 2005). The technique has been established to reproduce a large variety of wave sequences such as single abnormal waves as well as groups of rogue waves embedded in irregular sea states to investigate the response of floating structures to an extreme, but realistic, wave environment (Clauss et al. 2004).

In the tests the model is towed with an elastic suspension system using a triangular towing arrangement pulling the model without inducing a moment. The longitudinal motions are controlled with a spring in front and a counter weight behind the model. That way, heave and pitch motions remain unrestrained. The ship motions are measured with an optical motion tracking system on the centre of gravity. Figure 1 shows the scheme already described.

The generation of specific, tailor-made wave groups in the wave tank is based on the superposition of multiple wave components, with the nonlinear interaction between highorder wave components taken into account. With this technique is it possible to reproduce predefined wave sequences of large amplitude and highly nonlinear waves in the wave basin. It is possible to reproduce, at the model scale, single abnormal waves, as well as groups of rogue waves, embedded in irregular sea states. To transfer the recorded wave into the wave tank, the optimization approach for the experimental generation of tailored wave sequences with defined characteristics according to Clauss and Kühnlein (1996) was used.

Table 1 presents the ships' main particulars, where the longitudinal centre of gravity is measured from the midship and the vertical centre of gravity from the baseline, while Figs. 2 and 4 show the bodylines and Figs. 3 and 5 present photos of the models, which were segmented to measure structural loads, although the related results are not discussed here. Watanabe et al. (1989) and Clauss et al. (2009) presented a detailed analysis and discussion of the experimental setup.

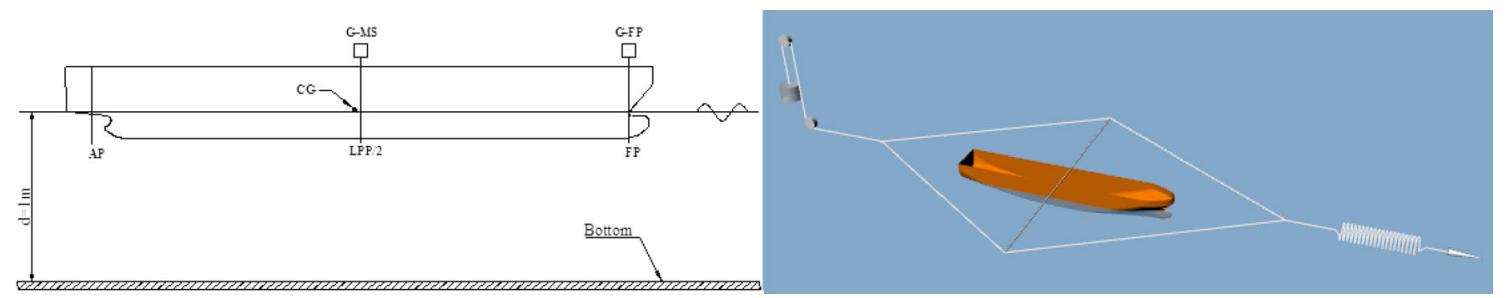

Fig. 1 Details of the experimental setup, the left picture shows the position of gauges G-MS and G-FP that measure the wave elevation at midship and at forward perpendicular, respectively. The right picture shows the triangular elastic suspension towing system

Table 1 Principal characteristics of ships

\begin{tabular}{lllll}
\hline & Symbol & Units & Bulk carrier & Ro-Ro vessel \\
\hline Length between perpendiculars & $L_{\mathrm{pp}}$ & $\mathrm{m}$ & 177 & 195 \\
Breadth moulded & $B$ & $\mathrm{~m}$ & 30 & 32.25 \\
Depth & $D$ & $\mathrm{~m}$ & 16.2 & 26.1 \\
Draught & $T$ & $\mathrm{~m}$ & 11.4 & 9.7 \\
Longitudinal centre of gravity & $L_{\mathrm{cg}}$ & $\mathrm{m}$ & 2.9 & -2.1 \\
Vertical central of gravity & $V_{\mathrm{cg}}$ & $\mathrm{m}$ & 5.9 & 10.5 \\
Transverse metacentric height & $G_{\mathrm{Mt}}$ & $\mathrm{m}$ & 6.2 & 5.2 \\
Block coefficient & $C_{\mathrm{b}}$ & - & 0.82 & 0.71 \\
Scale of the model & $\Lambda$ & - & 70 & 70 \\
Displacement & $\Delta$ & ton & 50,390 & 45,611 \\
Pitch radius of gyration & $K_{y y}$ & $\mathrm{~m}$ & 40.75 & 54.04 \\
\hline
\end{tabular}




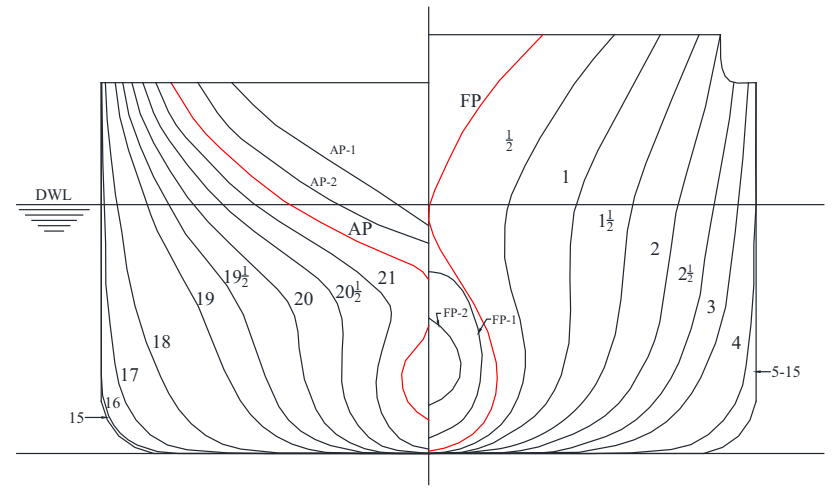

Fig. 2 Bulk carrier body lines

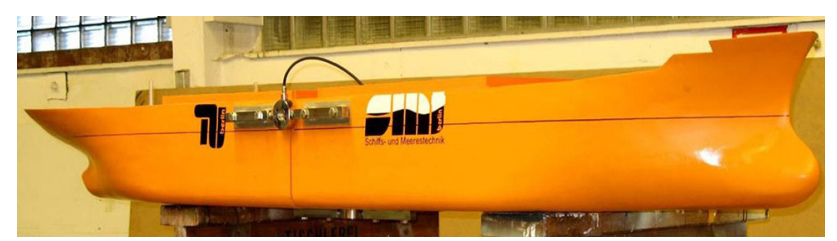

Fig. 3 Bulk carrier ship model

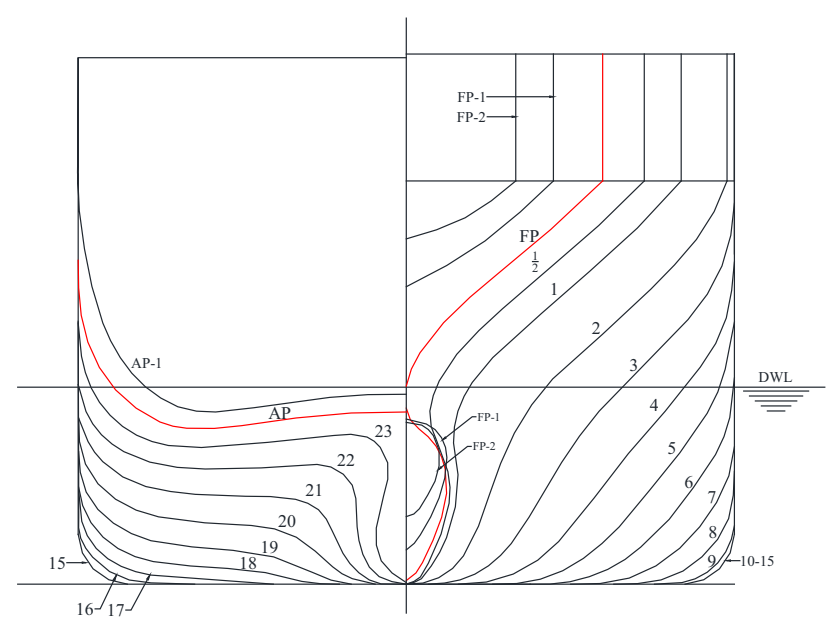

Fig. 4 Ro-Ro body lines

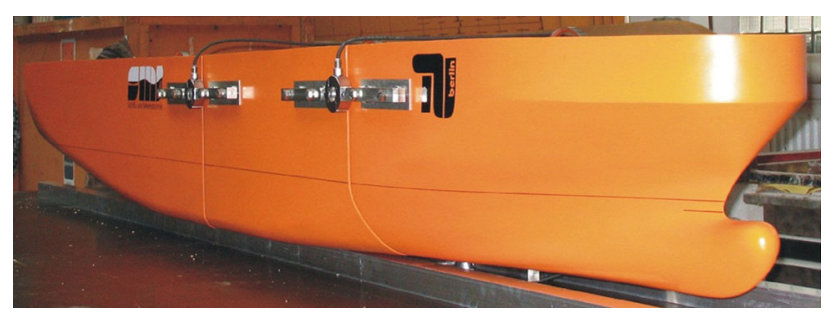

Fig. 5 Ro-on/Ro-off ship model

\subsection{Abnormal waves}

For the model tests two extreme wave events are selected (about $20 \mathrm{~min}$ of time record) that have been extracted from real-sea measurements. The related wave elevation time records were collected in the North Sea during storms. They are characterized by including an exceptionally high single wave with a height exceeding twice the significant wave height of the sea state. The two abnormal waves are named: the (well known) "New Year Wave" and "Single Abnormal Wave North Alwyn". The waves were generated on the seakeeping basin so that the highest wave elevation (Abnormal wave) can be found at midship. All the wave elevation presented here are referred to the midship position.

\subsubsection{New Year Wave $(N Y W)$}

One of the famous real-world records is the so-called "New Year wave". This wave was recorded during a storm on January 1, 1995 at the Draupner platform in the North Sea and was first reported by (Haver and Karunakaran 1998). A giant single wave $\left(H_{\max }=25.63 \mathrm{~m}\right)$ with a crest height of $\zeta_{c}=18.5 \mathrm{~m}$ occurred in a surrounding sea state characterized by a significant wave height of $H_{S}=11.92 \mathrm{~m}\left(H_{\max } / H_{s}=2.15\right)$. The water depth at the location is $d=70 \mathrm{~m}$. Figure 6 shows the record generated in the seakeeping basin. This wave record has been analysed by different methods (Walker et al. 2004; Slunyaev et al. 2005; Veltcheva and Guedes Soares 2007; Cherneva and Guedes Soares 2008) aiming to explain the formation and evolution of the abnormal wave. A detailed temporal and spatial development of the NYW generated in the seakeeping basin can be found in Clauss and Klein (2011) and its modelling was done by Petrova et al. (2011).

\subsubsection{Single Abnormal Wave North Alwyn (SAWNA)}

Figure 7 describes an abnormal wave recorded during a 5day storm (November 16 to 21, 1997) at the North Alwyn platform. North Alwyn is located $160 \mathrm{~km}$ east of the Shetland Islands in the North Sea. On November 19, 1997, a giant single wave with a wave height of $H_{\max }=22.03$ m was measured in a surrounding sea state of $H_{S}=8.64$ $\mathrm{m}\left(H_{\max } / H_{s}=2.55\right)$. This wave was reported by Guedes Soares et al. (2003) and was analysed with different methods in Slunyaev et al. (2005), Veltcheva and Guedes Soares (2007). The Fig. 7 shows the experimental record in the seakeeping basin. More detailed information about the experimental set up can be found in Clauss et al. (2008).

\section{Experimental and numerical results}

This section presents the experimental data, obtained in irregular seas that contain abnormal waves, and comparisons with numerical results obtained from numerical linear and nonlinear seakeeping numerical models. The nonlinear responses are calculated with a partially nonlinear numerical model which accounts for the nonlinear hydrostatic and Froude- 
Fig. 6 New Year Wave recorded sequence at the Draupner platform
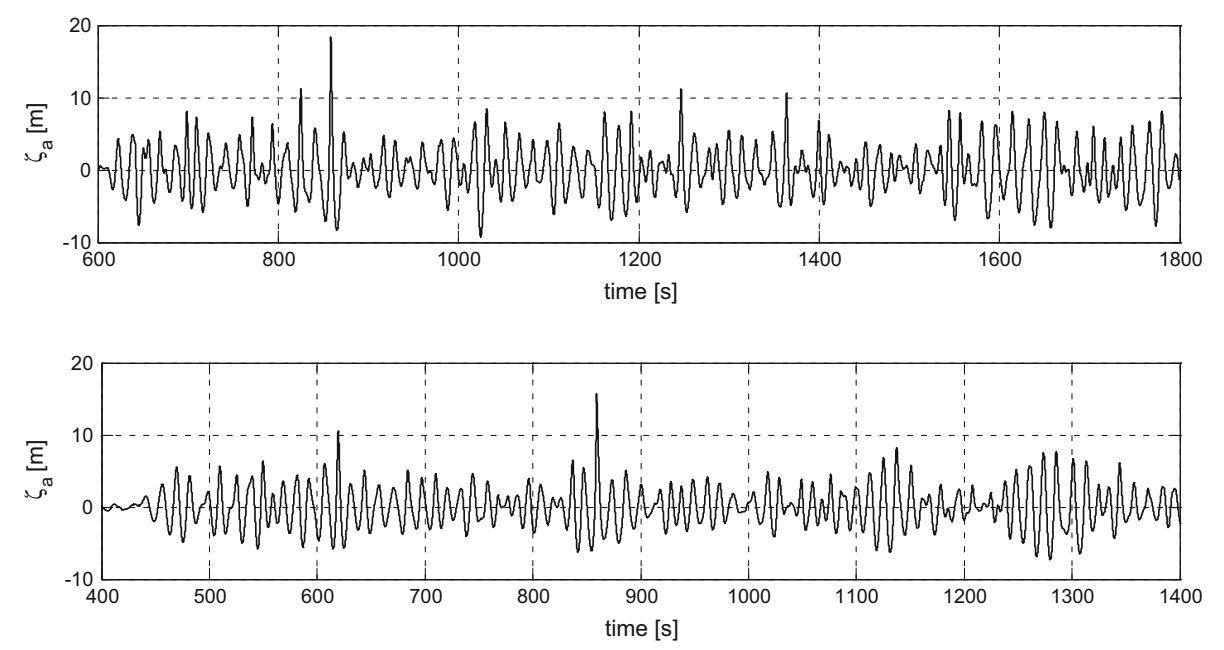

Fig. 7 Single abnormal Wave at North Alwyn recorded sequence at the North Alwyn platform
Krylov forces, while radiation and diffraction are linear. Green water loads due to water on deck is calculated by the momentum method. For all cases, the abnormal wave crest occurs at the midship cross section position. The technique developed by Clauss et al. (2006) allows the reproduction of a predefined wave trace in the ocean basin at a specific target location. The wave elevation at the target position is calibrated without the model in place. The same wave generator control signal is used during the runs with the ship model, which is strategically placed in the ocean basin to encounter the abnormal wave at midship.

The analysis is focused on the heave and pitch motions in head waves, and the objective is to assess the quality of numerical predictions in extreme wave conditions, and also to compare the responses from two different hulls to the same extreme wave conditions. Both ship models were tested in the same ocean basin, with the exact wave conditions and experimental setup, therefore, direct comparison of waveinduced motion behaviour is possible.

\subsection{Frequency domain analysis}

Figure 8 presents heave and pitch transfer function amplitudes for the bulk carrier (left graphs) and Ro-Ro ship (right graphs) in head waves and zero speed. Heave amplitudes are normalized by the wave amplitude, $\xi_{3} / \zeta_{a}$, and pitch amplitudes by the wave steepness, $\xi_{5} / k \zeta_{a}$, where $k$ is the wave number. The results are presented as function of the nondimensional encounter frequency, $\omega^{\prime}=\omega_{e} \sqrt{L_{\mathrm{pp}} / g}$, where $\omega_{e}$ is the encounter frequency, $L_{\mathrm{pp}}$ is the length between perpendicular and $g$ is the gravity acceleration. Dashed lines represent experimental data and continuous lines the linear numerical predictions. The experimental transfer function amplitudes were obtained by the transient wave package technique (Clauss and Kühnlein 1996). This is an efficient technique since the whole transfer function is derived from a single experimental run of relatively short duration. The transient wave package was characterized by small amplitude waves so that nonlinear response effects are minimized. The numerical results are calculated by the seakeeping linear numerical model.

The graphs show qualitatively similar results for both ships. For example, the ups and hollows of the transfer functions occur for the same nondimensional frequencies. The predictions compare well with the experimental data, except for the very low-frequency range, where, due to the small energy of the experimental sea state and ship responses, the spectral analysis is not reliable. The conclusion is that, within the linear regime, the motion responses are very similar for both ships. The linear predictions are accurate.

\subsection{Time domain analysis: abnormal waves}

This section presents direct time domain comparisons between experimental data and time domain simulations. Experimental data are represented by solid black lines, while numerical linear results are represented by dashed blue lines and nonlinear results by dashed red lines. Each figure corresponds to one incident wave and ship speed condition and it presents results for the two ships (under the same incident irregular wave). Each figure contains six graphs organized in two columns and three rows. The left graphs correspond to the bulk carrier and the right side graphs to the Ro-Ro ship. The first row graphs present the wave elevation, the second presents the heave motion and the third the pitch motion, all of them at centre of gravity.

Figure 9 shows the motion responses of both ships, at zero Froude number, induced by the New Year Wave (NYW). The highest wave elevation (abnormal wave) occurs between 190-200 and 195-210 s for the bulk carrier and the Ro-Ro ship, respectively. The largest heave motions occur approximately in phase with the wave elevation. The pitch time 
Fig. 8 RAO of heave and pitch for bulk (left) carrier ship and Ro-Ro vessel (right)
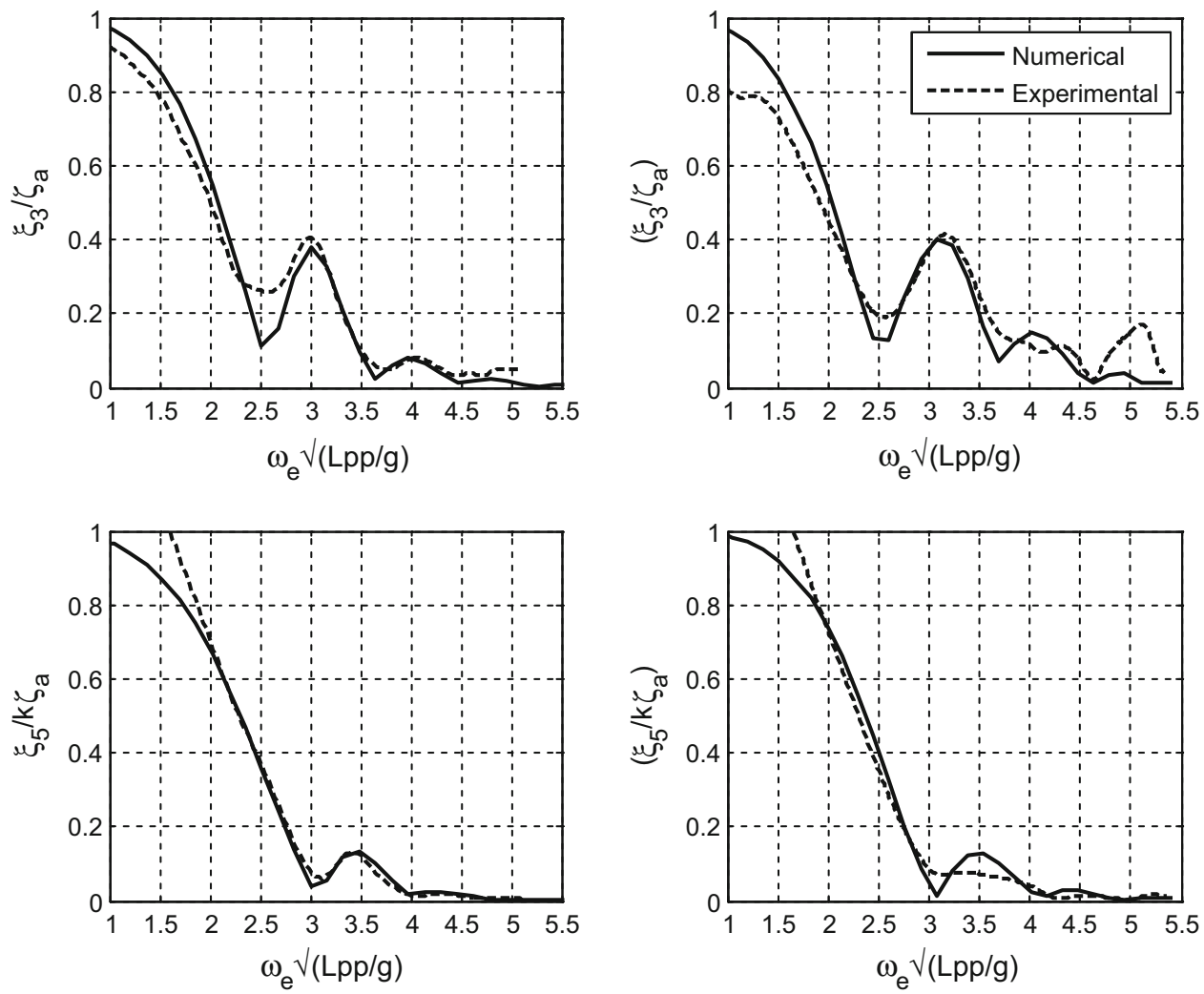

series is interesting because it presents three large peaks, two negative and one positive. The first large pitch peak is negative and it corresponds to the moment when the abnormal wave crest is on the forward part of the hull raising the ship's bow, the second peak is positive and it occurs when the large wave crest is at the stern and the ship dives the bow into the next wave, the third large pitch peak is negative again. Figure 10 shows results similar to those of Fig. 9, but in this case for the single abnormal wave time record that was measured at North Alwyn (SAWNA). The large wave crest occurs between 340-360 and 370-390 s for bulk carrier and Ro-Ro ship, respectively. The experimental motion results are qualitatively similar to the ones induced by the NYW.

Comparing the two ships' experimental motions responses, one concludes that they are very similar in terms of maximum motions induced by the abnormal wave: the NYW induces maximum heave responses for the two ships between 5.5 and $6.0 \mathrm{~m}$ and maximum pitch motions between $9^{\circ}$ and $10^{\circ}$. The same close agreement is observed for the motions induced by the SAWNA.

In terms of simulated results, the agreement with experimental data is surprisingly good, given the fact that these are extreme wave conditions for which nonlinear effects are expected to be at their highest level. The predictions are better for the bulk carrier than for the Ro-Ro ship. Comparing the linear and nonlinear solutions, they are similar for the bulk carrier and slightly larger differences are observed for the
Ro-Ro. The nonlinear effects tend to produce larger heave and pitch crests and smaller heave troughs. This is related to the ship's flare at the bow and stern and related large increase of buoyancy forces (hydrostatic plus Froude-Krylov) by the nonlinear method, compared with the linear method, when the ship hull submerges.

Although linear and nonlinear results are very close for the bulk carrier, in fact the linear predictions compare even better with the experiments. Regarding the Ro-Ro, the nonlinear results tend to agree better with the experiments.

Figures 11 and 12 show motion response time series for the ships advancing in head waves (NYW and SAWNA), with a speed corresponding to a Froude number $F n=0.1$, heave and pitch experimental maximum motions have increased significantly compared to the condition without forward speed (in average around $20 \%$ ). The maximum motions induced on the two ships by the same waves are still very similar.

The agreement between experiments and numerical predictions is again good, except for the bulk carrier encountering the SAWNA where the calculations over predict the experiments. Figures 9, 10, 11 and 12, with the time histories of measurements and calculations, are focused around the abnormal wave events; therefore, they show the motion response characteristics to these extreme events. To obtain a more general overview of the motion response characteristics in severe sea states, a large number of positive and negative 

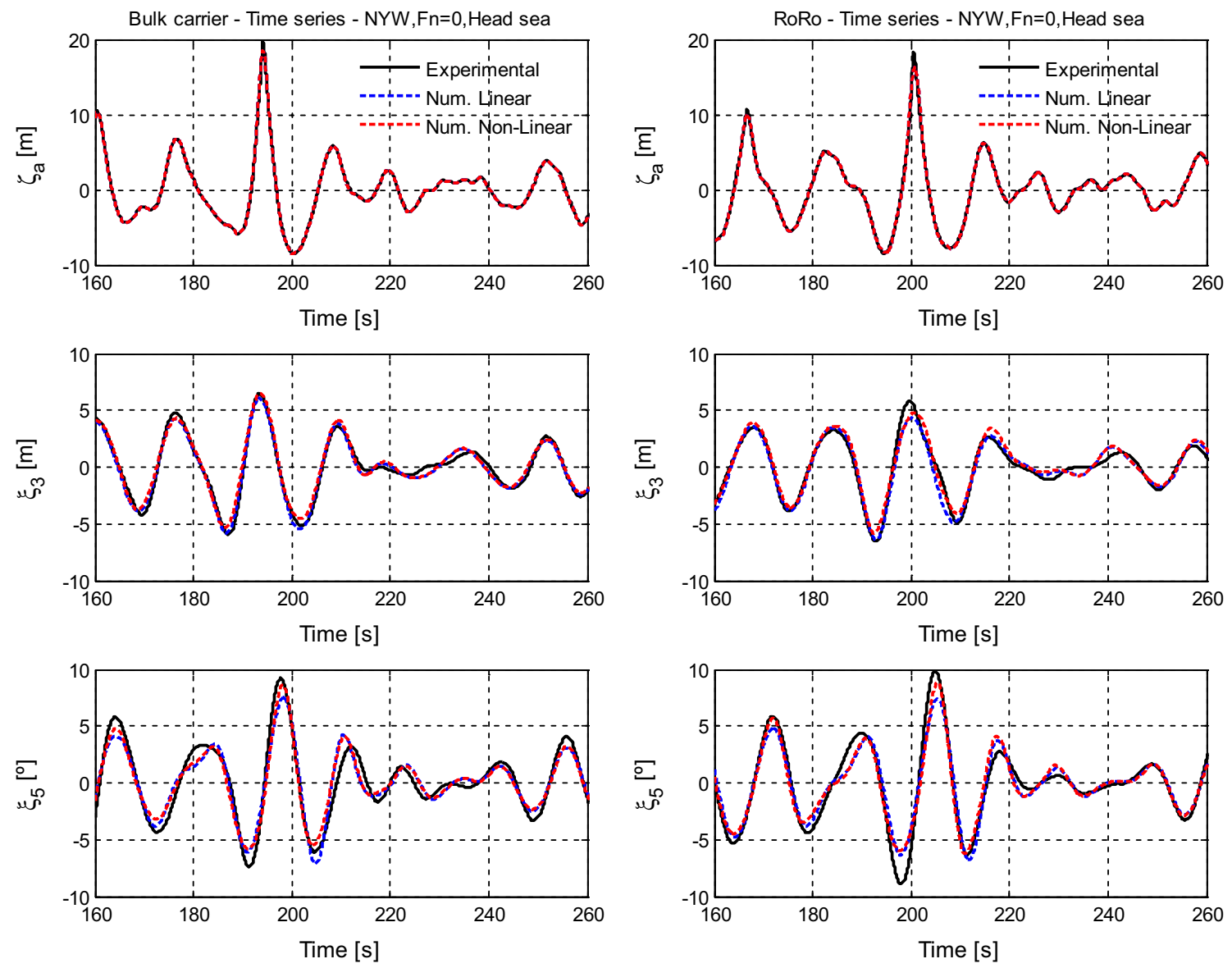

Fig. 9 Time series for wave elevation, heave and pitch. The first column is for the bulk carrier and the second column is for the Ro-on/Ro-off, both in head sea and $F n=0$ at NYW

peaks from the experiments and numerical simulations are compared to each other. They were obtained from time histories with duration of $30 \mathrm{~min}$ (full scale) in the severe sea states where the abnormal waves were measured. Figures 13 and 14 show these results for the NYW at zero Froude number and, respectively, heave and pitch results. Figures 15 and 16 present similar results corresponding to the Froude number of 0.1. Left graphs present linear predictions versus experimental data, while the right graphs present nonlinear results versus experimental data. Each graph includes positive and negative peaks, and their correlation with experiments for the bulk carrier (circles) and for the Ro-Ro (triangles). Each point corresponds to one peak induced by a crest or trough, where the horizontal axis value gives the experimental result and the vertical axis the numerical prediction.

The graphs show that the predictions by the linear method are good, especially for the zero-speed condition. The nonlinear effects tend to increase slightly the heave and pitch peaks for the largest waves, and the correlation of the positive peaks with the experiments improves slightly, while the opposite occurs for the negative peaks. No qualitative differences are observed between the two ships. The results and conclusions are similar for the forward speed case, although a larger dispersion of results is observed.

\section{Numerical predictions and discussion of nonlinear influence in motion}

The previous sections presented heave and pitch motion response comparisons between experimental data and linear and nonlinear simulations for extreme wave conditions. The numerical results compare well with the experimental data, even for rogue wave conditions. It was also concluded that, in terms of response peaks, the nonlinear effects are small. The first-order and higher harmonic content of the motion responses to incident harmonic waves is one other indicator of the response nonlinearity level. This section presents an analysis of the first- and second-order motion response harmonics in incident harmonic waves and their dependence on the wave steepness.

The nonlinear effects on the ship vertical responses are in part related to the hull geometry. Ships with small block coefficient are characterized by significant flare on the bow 

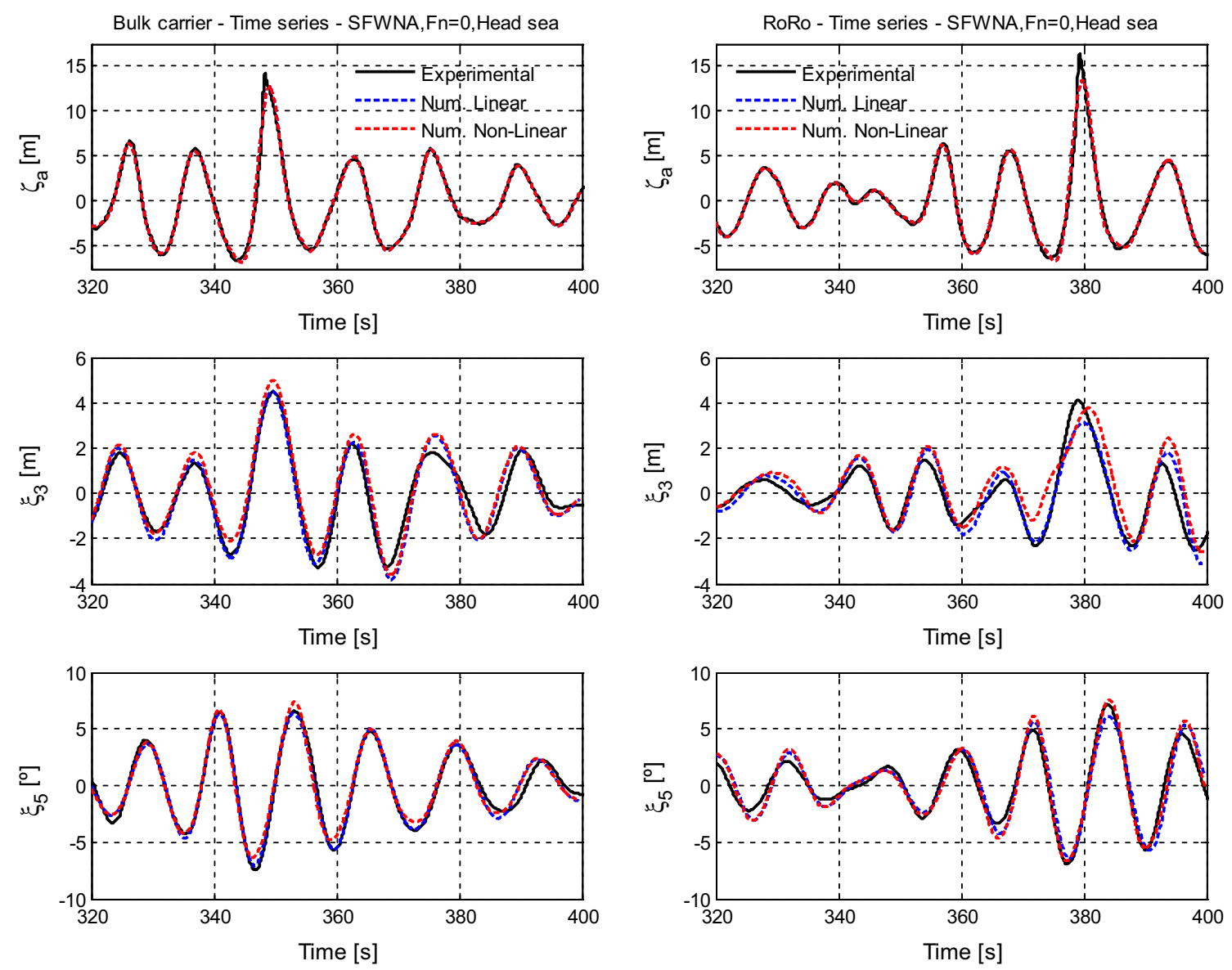

Fig. 10 Time series for wave elevation, heave and pitch. The first column is for the bulk carrier and the second column is for the Ro-on/Ro-off, both in head sea and $F n=0$ at SAWNA

and stern. In these cases, the linear assumption of hull vertical sides fails and the consequence might be important nonlinear effects. In fact, due to large relative motions, the hydrostatic and Froude-Krylov vertical forces are highly nonlinear for the ship's flared cross sections. It is interesting to compare the hull geometries of the two ships under investigation. The hull body lines of Figures 2 and 4 show that the Ro-Ro has a more flared hull than the bulk carrier. However, it is useful to quantify the differences between the hulls and, with this objective in mind Fig. 17 shows the breadth and flare, at the waterline, along the ship length. The breadths (upper graph) are normalized by the ship length between perpendiculars $\left(\mathrm{L}_{\mathrm{pp}}\right)$, while the flare (lower graph) is defined by the cross section slope $(\mathrm{d} y / \mathrm{d} z)$ calculated at the waterline. These characteristics are presented as function of the ship's longitudinal position ( 0 at the forward perpendicular) divided by $L_{p p}$. The dashed lines represent the bulk carrier and the continuous lines the Ro-Ro ship.

The bulk carrier bow has a larger water plane area, but the Ro-Ro flare is much larger, therefore, larger nonlinear effects are expected for the Ro-Ro ship. The opposite is observed for the stern area, where the bulk carrier has a smaller water plane area and larger flare. One should note that the relative motions are much smaller in the stern area than at the bow.

The bulk carrier and the Ro-Ro ships are analysed in regular waves within a range of frequencies from 0.2 to 1.20 $(\mathrm{rad} / \mathrm{s})$ and four different wave steepnesses represented by the wave length over wave height ratio $\left(L_{w} / H_{w}\right)$. The four ratios range from small amplitude to large amplitude waves $\left(L_{w} / H_{w}=40,60\right.$ and 80$)$. Nonlinear time domain simulations are carried out for all harmonic wave conditions and Fourier analysis carried out to identify the responses harmonic content.

Figure 18 presents heave and pitch first harmonic motion amplitudes for the bulk carrier and Ro-Ro in head harmonic waves and zero speed. Figure 19 shows similar results corresponding to a Froude number of 0.1 . Heave and pitch amplitudes as well as frequency are nondimensionalized following the same criteria which was described in the frequency domain analysis, where RAO was presented (see Fig. 8).

The two interesting observations from the graphs are: the ships motions are in practice linear, in terms of nondimensional first harmonic amplitudes; the transfer functions are 

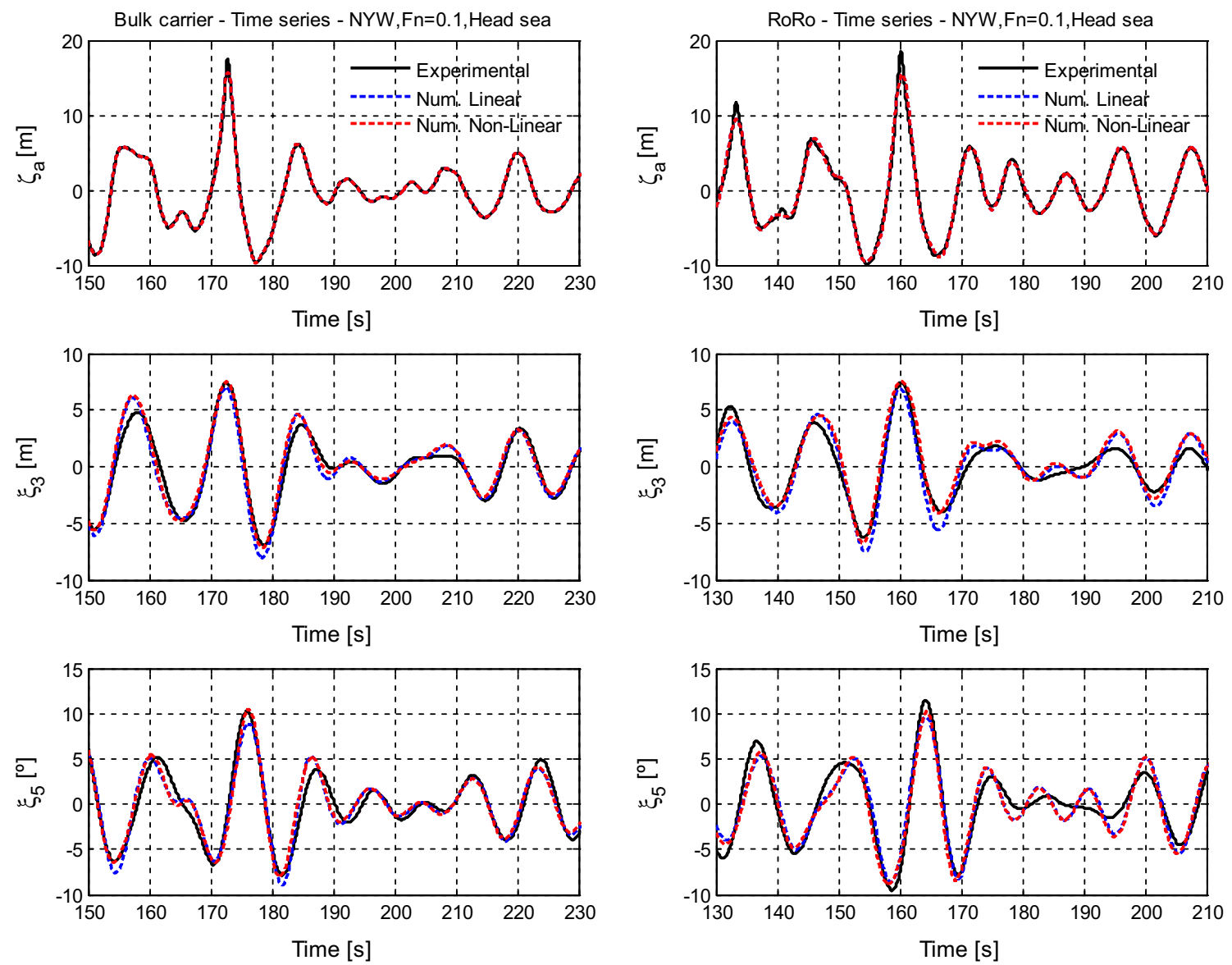

Fig. 11 Time series for wave elevation, heave and pitch. The first column is for the bulk carrier and the second column is for the Ro-on/Ro-off, both in head sea and $F n=0.1$ at NYW

almost identical for the two ships. The first conclusion is different from the one presented by Fonseca and Guedes Soares (2004b, c, 2005) for a containership $\left(C_{\mathrm{b}}=0.572\right)$. The experimental and numerical results from these authors showed a decrease of the nondimensional amplitudes of heave and pitch of up to $20 \%$, with the increase of wave steepness. The reason for the different behaviour compared to the bulk carrier and Ro-Ro is probably related to the higher Froude number considered for the containership $(F n=0.25$ compared to $F n=0$ and 0.1 ), which results in a dynamic amplification of heave and pitch around the natural frequencies.

Figures 20 and 21 show the wave steepness influence on the second harmonics of heave and pitch for the 0 and 0.1 Froude number conditions. The second harmonic amplitudes are normalized by the wave amplitude, so that comparisons with the nondimensional first harmonic amplitudes are easy. One observes that the second harmonics are quite large and increase very much with both the wave steepness and the ship speed. For the largest wave steepness and Froude number of 0.1 , heave second harmonics reach more than $20 \%$ of the first harmonic values, while for pitch reach close to $40 \%$ of the first harmonics. In this regard, the vertical motions are strongly nonlinear. The second harmonics are concentrated around relatively narrow frequency ranges, with peaks around the nondimensional encounter frequency of 1.2 for heave and 1.4 for pitch. These correspond to wavelength to ship length ratios of 4.4 and 3.2. Comparing the second harmonics for the two ships, they are very similar for pitch, while the bulk carrier shows slightly larger values for heave.

It is interesting to qualitatively compare the main conclusions from the present study regarding the heave and pitch motions, with similar results concerning the cross-sectional vertical shear forces and vertical bending moments. Such analysis for the wave-induced structural loads has been carried out before for a containership (Fonseca and Guedes Soares 2004b), a frigate (Fonseca and Guedes Soares 2004a) and an offshore platform with a hull shape similar to a tanker (Fonseca and Guedes Soares 2002). It is possible to say that the main difference is related to the cross-sectional loads time history asymmetry for small block coefficient ships- the sagging peaks magnitudes in large amplitude waves are much larger than the hogging ones. Much smaller differences are 

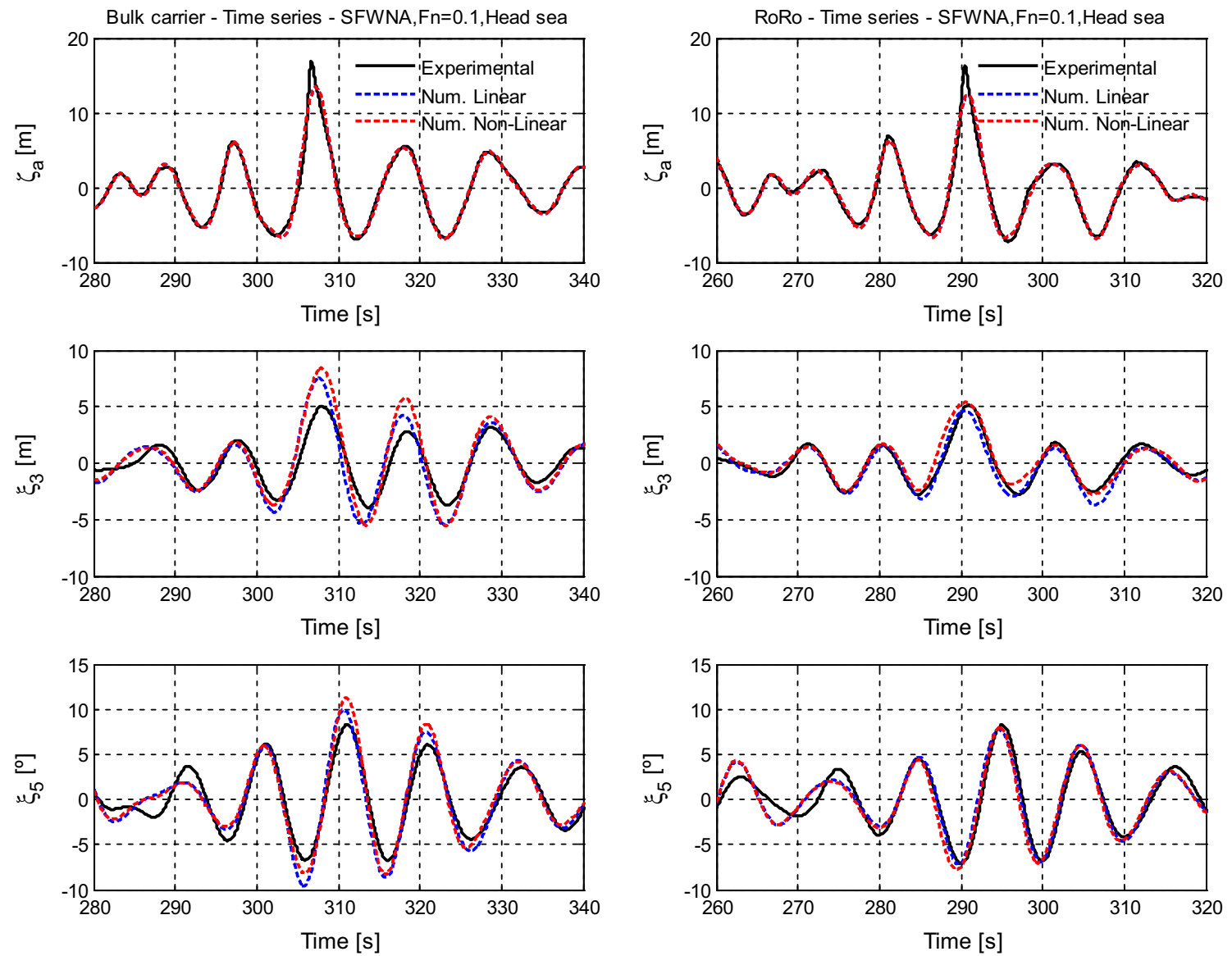

Fig. 12 Time series for wave elevation, heave and pitch. The first column is for the bulk carrier and the second column is for the Ro-on/Ro-off, both in head sea and $F n=0.1$ at SAWNA

Fig. 13 Crest and trough of heave time series in head sea with $F n=0$
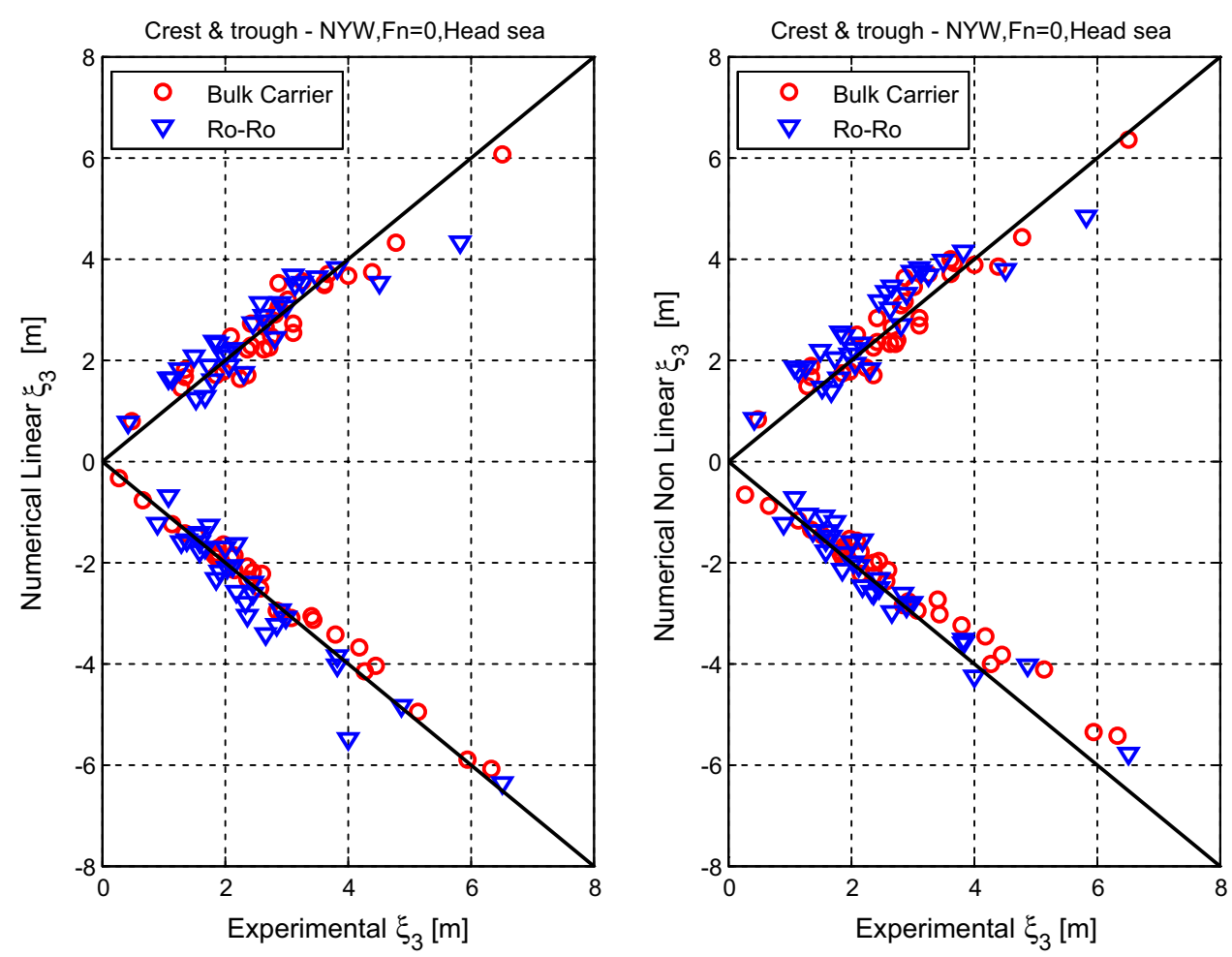
Fig. 14 Crest and trough of pitch time series in head sea with $F n=0$

Fig. 15 Crest and trough of heave time series in head sea with $F n=0.1$
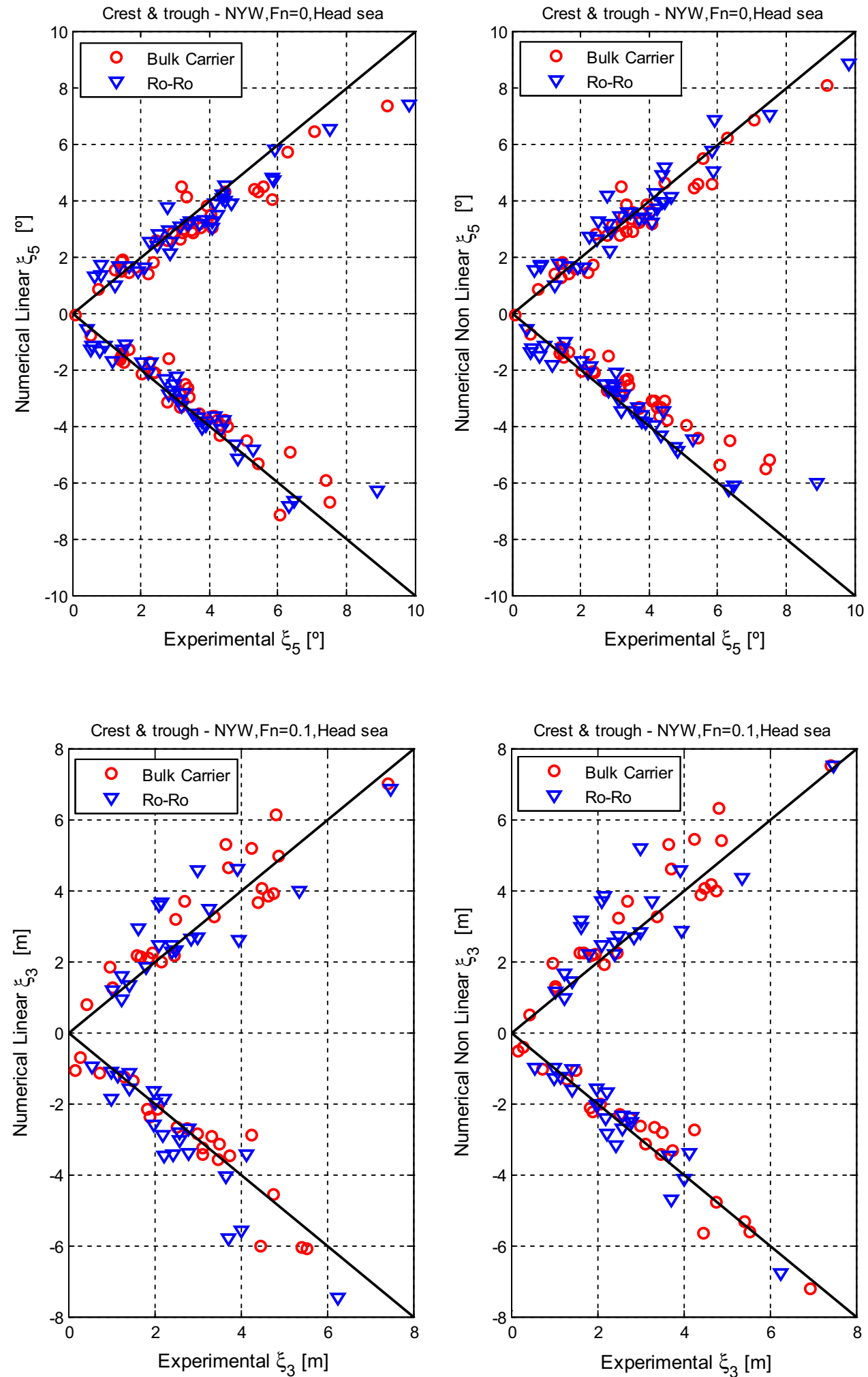

observed for large block coefficients ships. Such asymmetry is not observed for the vertical motions.

Regarding the first harmonic nondimensional amplitudes, it was observed before (Fonseca and Guedes Soares 2004a) that the vertical bending moment at the bow of a containership (cross section located at $\mathrm{L}_{\mathrm{pp}} / 4$ ) increases significantly with the wave steepness in regular waves, while it is nearly constant at midship. 
Fig. 16 Crest and trough of pitch time series in head sea with $F n=0.1$

Fig. 17 Breadth and flare of the bulk carrier and Ro-Ro ship
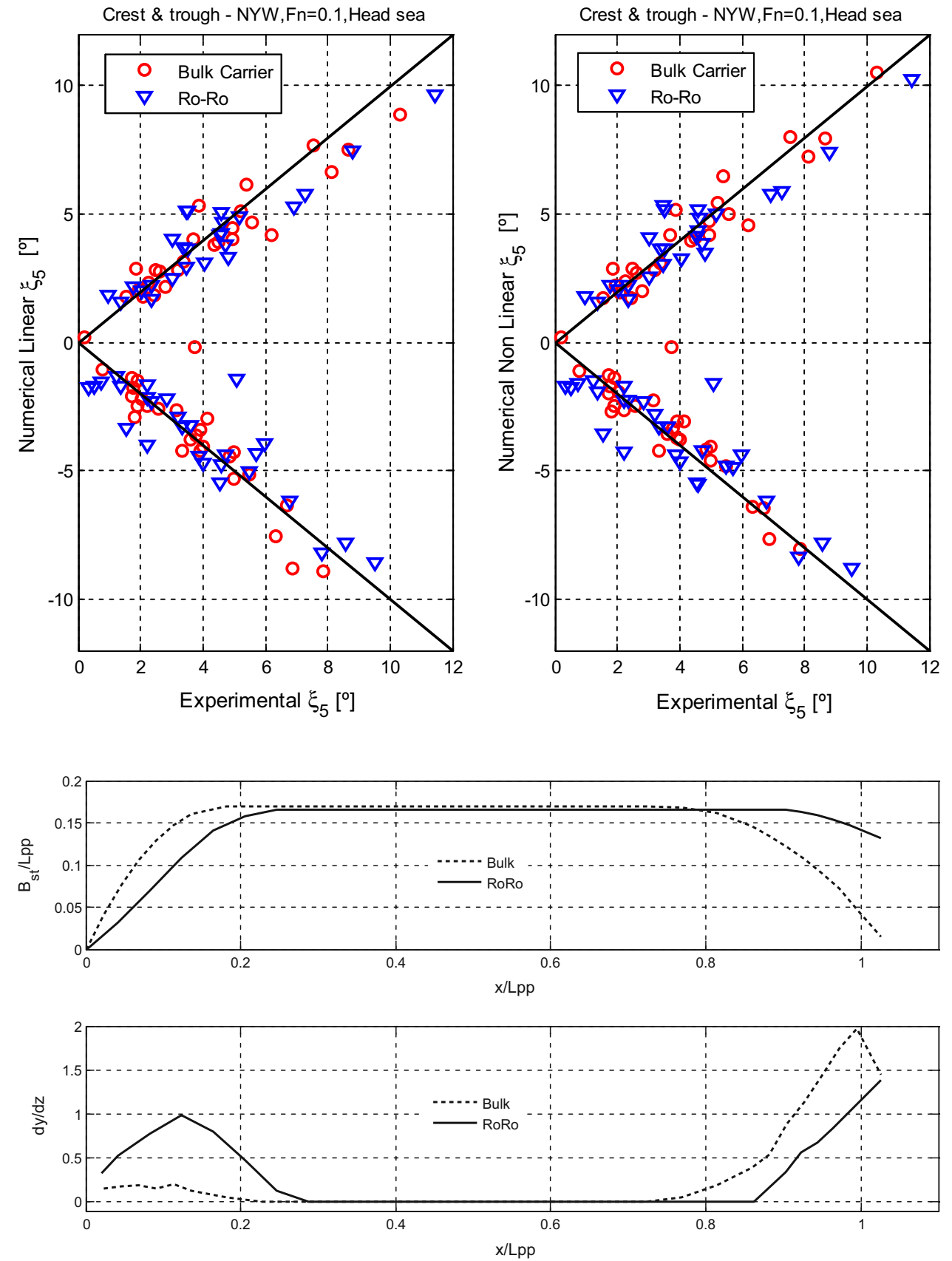

\section{Discussion of uncertainties}

The International Towing Tank Conference (ITTC) recommends that an uncertainty analysis is carried out for Experimental Fluid Dynamics results (Recommended Procedure 7.5-02-01-01). The errors can be separated into bias (systematic) and precision (random) and they depend on a number of elemental error sources. It is necessary to identify the elemental error sources and propagate them through the data reduction equations to the measured quantities. In practice the uncertainty analysis is rarely carried out for seakeeping tests, since it is difficult to identify all relevant elemental errors and the data reduction equations.

The fact that the present experimental study focuses on responses to irregular large amplitude waves, instead of steady-state responses in regular waves, increases further the complexity of an uncertainty analysis. For this reason the uncertainty analysis was not planned from the beginning in the experimental work conducted by Clauss et al. (2009). A qualitative analysis can, however, be carried out. Errors associated with the geometry of the model and the measurement of the centre of gravity position and radii of 

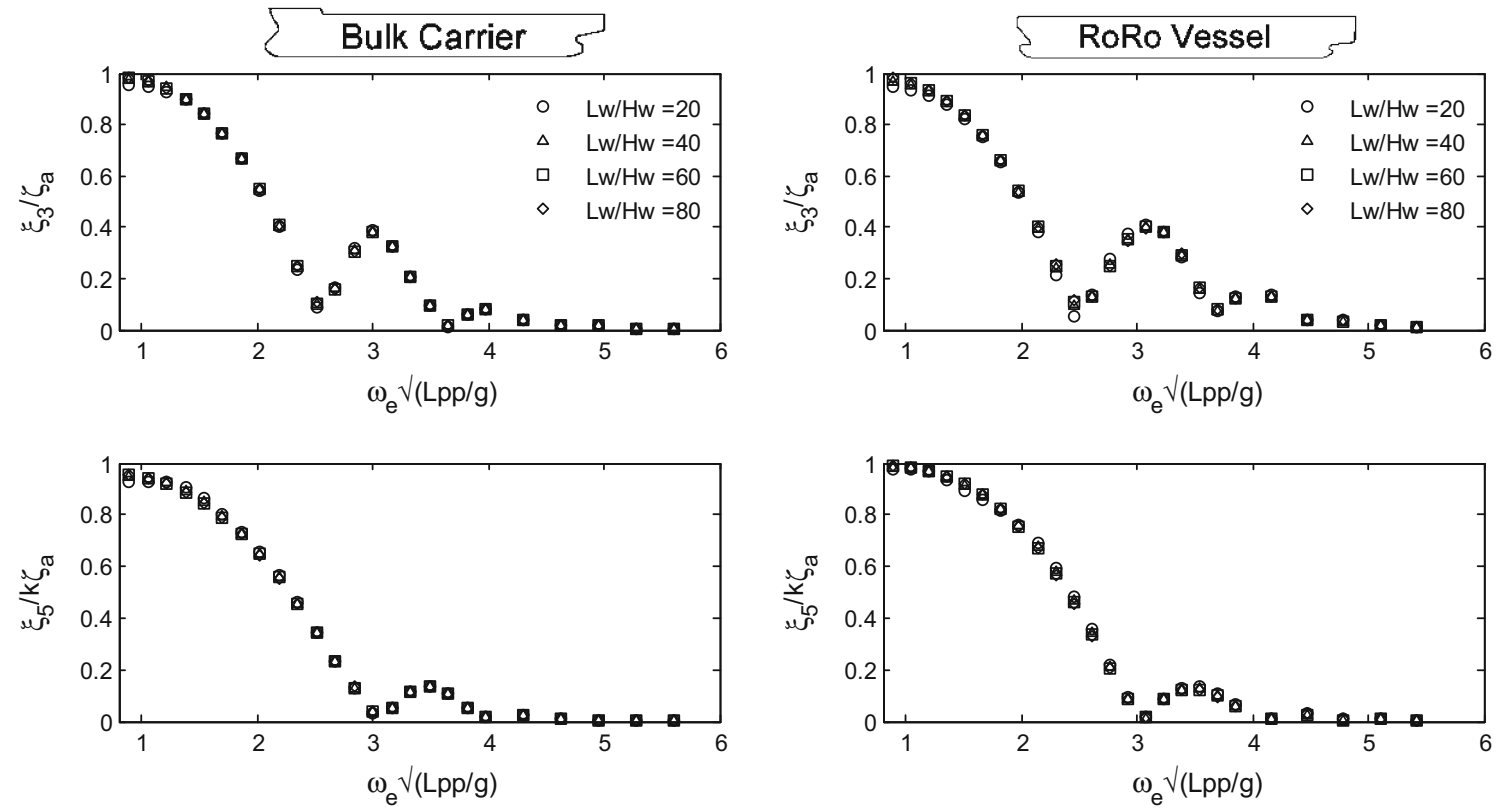

Fig. 18 First harmonic amplitudes of heave and pitch for different wave steepnesses in head waves and $F n=0$
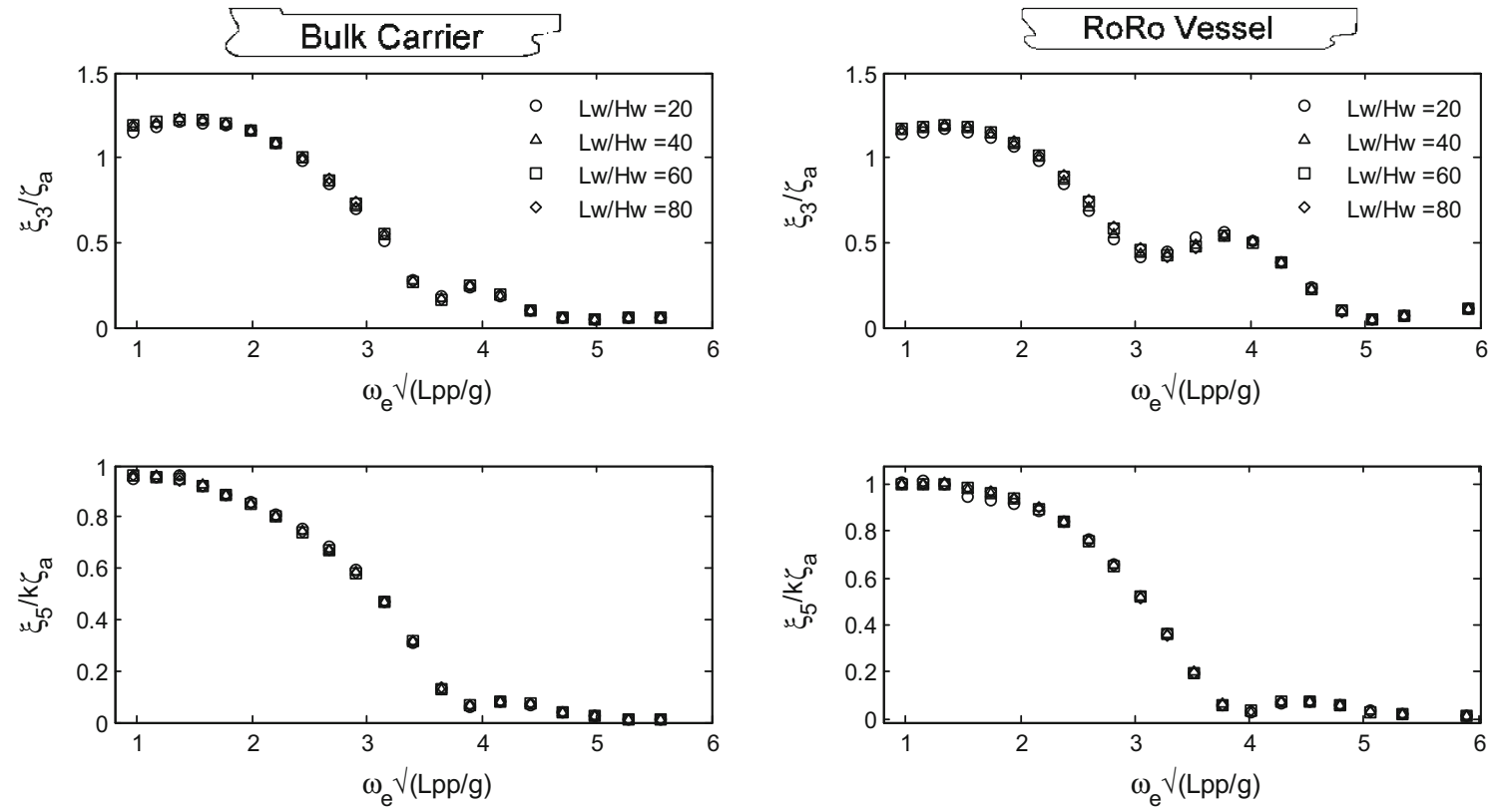

Fig. 19 First harmonic amplitudes of heave and pitch for different wave steepnesses in head waves and $F n=0.1$

gyration are very small. The accuracy of modern sensors (for the wave elevation sensor, absolute motion, relative motions, and bending moments) is also very good. For these reasons, Irvine et al. (2008) calculated the uncertainty on the amplitude of the heave and pitch motions of the order of $1 \%$. It is expected that the uncertainties related to the absolute motions and vertical bending moments for the present experimental results to be of the same order of magnitude.

Regarding the numerical model, the development of the related computer code follows two steps, as usual. The first step is the verification which consists of verifying that the code is correct in terms of implementation of the numerical model. This has been done during the programming and debugging phase. Furthermore, for the present study, convergence with respect to the discretization of the hull has been achieved, as well as convergence of the time domain numerical integration of the equations of motion with respect to the time step. The second step is the validation, consisting on the demonstration that the mathematical model of the verified computer code is an adequate representation of the physical reality. Some validation work has been done before (Fonseca 

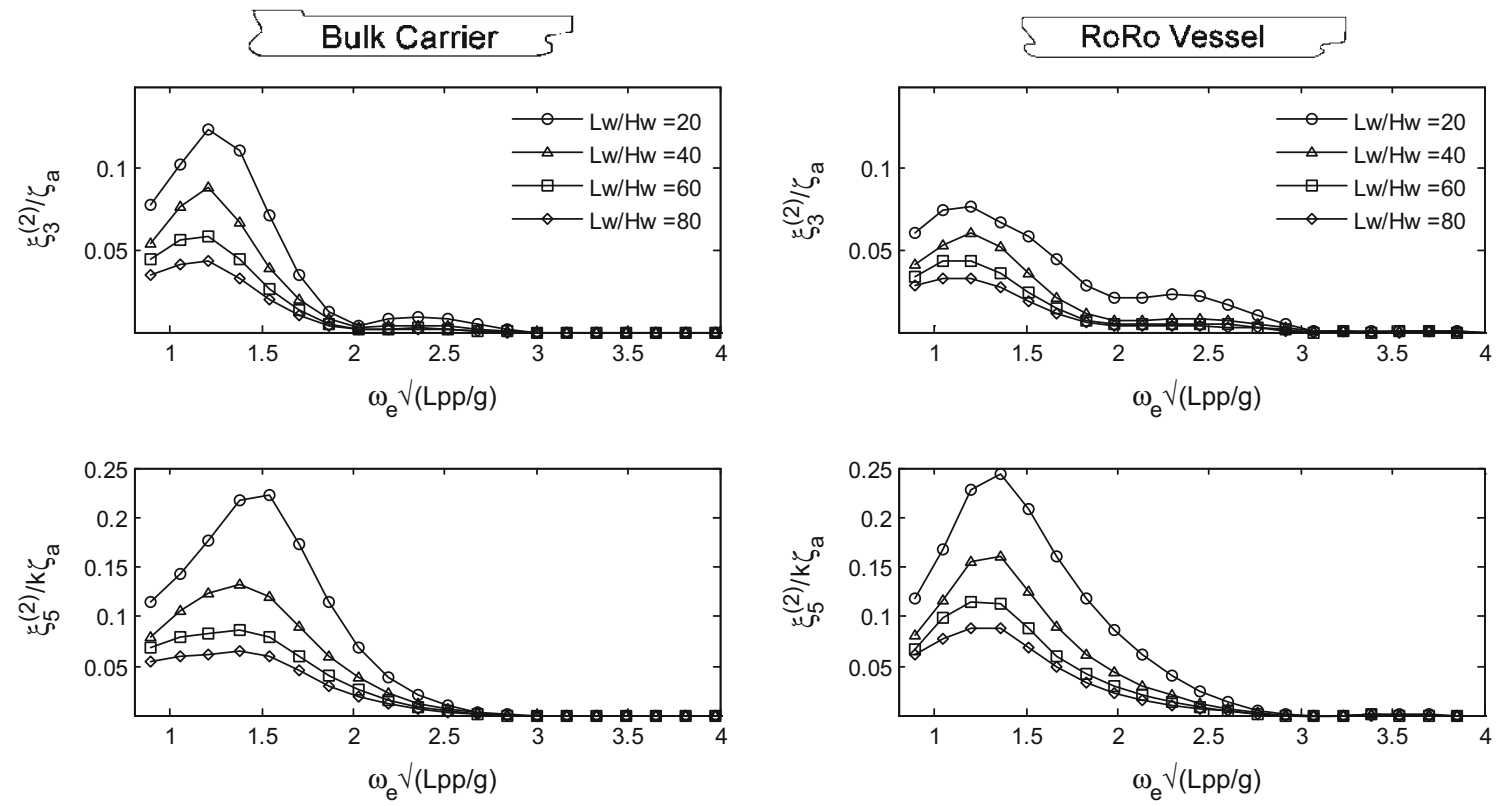

Fig. 20 Second harmonics of heave and pitch for different wave steepnesses in head waves and $F n=0$
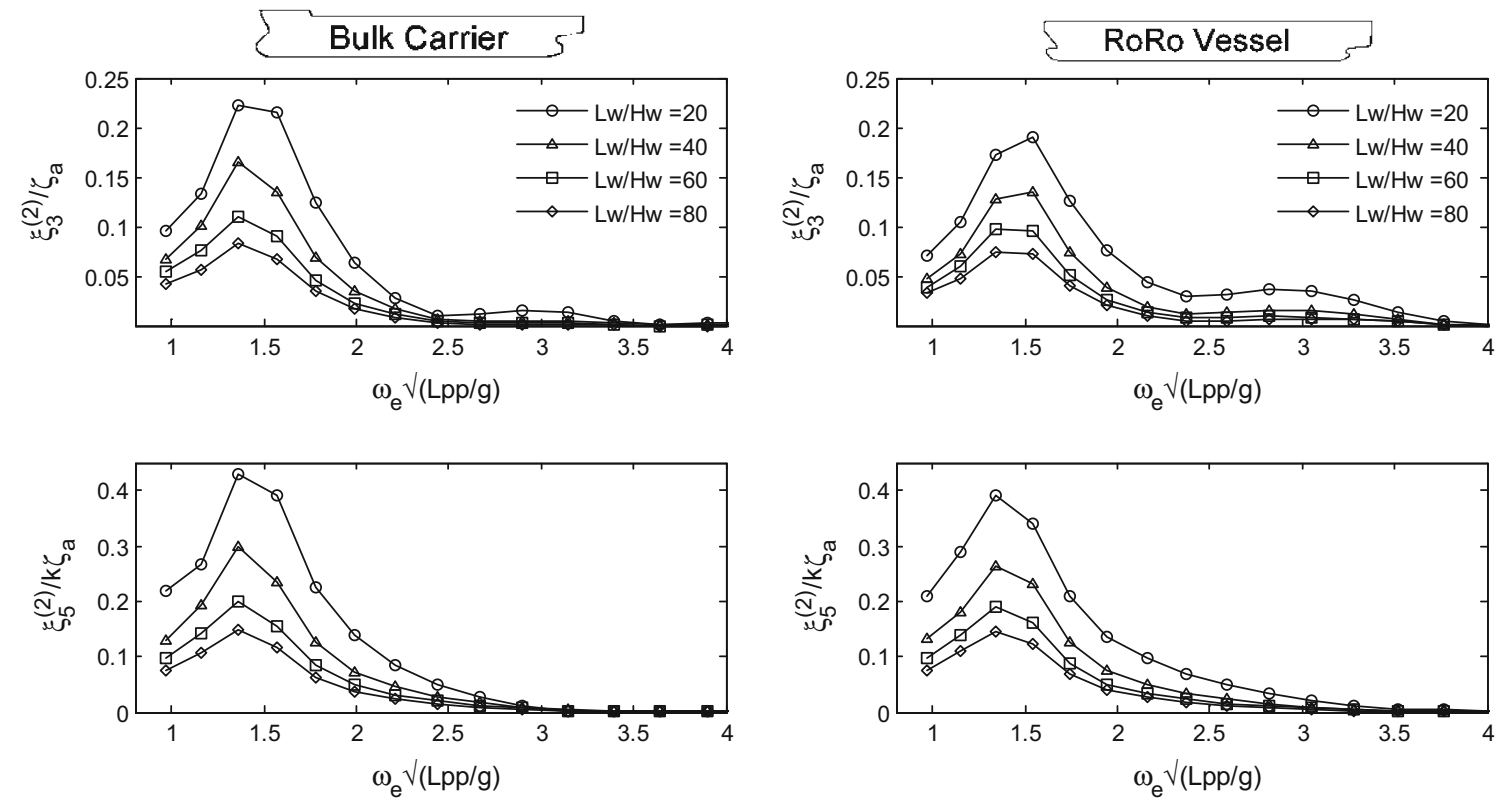

Fig. 21 Second harmonics of heave and pitch for different wave steepnesses in head waves and $F n=0.1$

and Guedes Soares 2002, 2004a, b), and further validation is carried out with the present study.

\section{Conclusions}

The paper presents an analysis of the vertical motions induced by large amplitude waves on a bulk carrier and a Ro-Ro. The objective is to assess how the ship hull geometry influences the motion response characteristics in extreme seas, including the influence on the nonlinear behaviour. With this objective in mind, two ship models with similar length and different block coefficients $\left(C_{\mathrm{B}}=0.82\right.$ and $\left.C_{\mathrm{B}}=0.71\right)$ and bow flare are tested in a seakeeping basin in exactly the same incident waves conditions. The wave conditions correspond to wave records measured during real storms and they include abnormal waves.

Comparison of the experimental results for the two ships show very similar heave and pitch responses. The same conclusion is obtained by comparing numerical predictions from linear and nonlinear seakeeping numerical models. No relevant differences were detected in the vertical motion 
responses of two ships with different block coefficients. The second interesting conclusion is that the simplified numerical codes, based on linear potential flow theory and strip theory hypothesis, are able to predict quite well heave and pitch induced by extremely large waves. Furthermore, nonlinear predictions are similar to the linear ones in terms of responses to the abnormal waves. Also in this aspect no significant differences were detected between the results for the two ships.

The linear heave and pitch behaviour, even in large amplitude waves, is confirmed by computing pseudotransfer function amplitudes for several wave steepnesses-the nondimensional first harmonic amplitudes are nearly independent of the wave steepness. Nonlinear behaviour is identified by the higher harmonic content on the motion responses induced by large amplitude harmonic waves. Second harmonic amplitudes reach around $20 \%$ of the first harmonics for heave and $40 \%$ for pitch.

One practical conclusion can be taken from the present study: the linear seakeeping method can be used to calculate the heave and pitch motions even in extreme waves. The conclusion is valid for conventional hull forms and small Froude numbers typical of the ship's speed in heavy seas, while previous studies have shown some nonlinear effects at higher Froude numbers, namely when heave and pitch transfer functions show some dynamic amplification typical of higher speeds.

Acknowledgments The work has been performed in the scope of the project "HANDLING WAVES-Decision Support System for Ship Operation in Rough Weather", (www.mar.ist.utl.pt/handlingwaves/), which is funded by the European Union through the Growth program under contract TST5-CT-2006-031489.

\section{References}

Adegeest LJM (1995) Nonlinear hull girder loads in ships. Ph.D Thesis, Faculty of Mechanical Engineering and Marine Technology, Delft University of Technology, The Netherlands

Bertotti L, Cavaleri L (2008) Analysis of the Voyager storm. Ocean Eng 35(1):1-5

Buchner B (1995) On the impact of green water loading on ship and offshore unit design. In: Kim H, Lee JW (eds) The sixth international symposium on practical design of ships and mobile units. The Society of Naval Architects of Korea, pp 430-443

Cavaleri L, Bertotti L, Torrisi L, Bitner-Gregersen E, Serio M, Onorato M (2012) Rogue waves in crossing seas: the Louis Majesty accident. J Geophys Res 117:C00J10. doi:10.1029/2012JC007923

Cherneva Z, Guedes Soares C (2008) Non-linearity and non-stationarity of the New Year Abnormal Wave. Appl Ocean Res 30:215-220

Clauss G (2002) Dramas of the sea: episodic waves and their impact on offshore structures. Appl Ocean Res 24:147-161

Clauss G, Kühnlein W (1996) Nonlinear transient wave excitation as a new tool in model testing. In: Proceeding of the 15th international conference on Offshore Mechanics and Arctic Engineering (OMAE 96), paper OMAE 96-552, vol 1. Florence, Italy, pp 41-48
Clauss GF, Schmittner CE (2005) Experimental optimization of extreme wave sequences for the deterministic analysis of wave/structure interaction. In: Proceedings of the 24th international conference on Offshore Mechanics and Arctic Engineering (OMAE 2005), ASME, paper no OMAE2005-67049

Clauss GF, Klein M, Dudek M (2010) Influence of the bow shape on loads in high and steep waves. In: Proceedings of the 29th international conference on Ocean, Offshore and Arctic Engineering (OMAE 2010), ASME, paper no OMAE2010-20142

Clauss GF, Klein M, Kauffeldt A (2009) Limiting loads and motions of ships in extreme sea states. In: Proceedings of 13th Congress of International Maritime Association of Mediterranean, Istanbul, Turkey

Clauss GF, Klein M (2011) The New Year Wave in a seakeeping basin: generation, propagation, kinematics and dynamics. Ocean Eng 38(14-15):1624-1639

Clauss GF, Schmittner CE, Hennig J, Guedes Soares C, Fonseca N, Pascoal R (2004) Bending moments of an FPSO in rogue waves. In: Proceedings of the 23rd international conference on Offshore Mechanics and Arctic Engineering (OMAE 2004), ASME, paper no OMAE2004-51504

Clauss GF, Schmittner CE, Hennig J (2008) Systematically varied rogue wave sequences for the experimental investigation of extreme structure behavior. J Offshore Mech Arct Eng 130(2):021009

Clauss GF, Schmittner CE, Klein M (2006) Generation of rogue waves with predefined steepness. In: Proceedings of the 25th international conference on Offshore Mechanics and Arctic Engineering, ASME, pp 319-325

Didenkulova II, Slunyaev AV, Pelinovsky EV, Kharif C (2006) Freak waves in 2005. Nat Hazards Earth Syst Sci 6(6):1007-1015

Faulkner D, Buckley WH (1997) Critical survival conditions for ship design. In: Proceedings of the international conference on design and operation for abnormal conditions, RINA, Oct 21-22, Glasgow, UK, paper no. 6, pp 1-25

Fonseca N, Guedes Soares C (1998a) Time-domain analysis and wave loads of large-amplitude vertical ship motions. J Ship Res 42(2):139-153

Fonseca N, Guedes Soares C (1998b) 'Nonlinear wave induced responses of ships in irregular seas. In: Proceedings of the 17th international conference on Offshore Mechanics and Arctic Engineering (OMAE 98), ASME, Lisbon, Portugal, paper no OMAE1998-0446

Fonseca N, Guedes Soares C (2002) Comparison of numerical and experimental results of nonlinear wave-induced vertical ship motions and loads. J Mar Sci Technol 6(4):193-204

Fonseca N, Guedes Soares C (2004a) Validation of a time-domain strip method to calculate the motions and loads on a fast monohull. Appl Ocean Res 26(6):256-273

Fonseca N, Guedes Soares C (2004b) Experimental investigation of the nonlinear effects on the statistics of vertical motions and loads of a containership in irregular waves. J Ship Res 48(2):148-167

Fonseca N, Guedes Soares C (2004c) Experimental investigation of the nonlinear effects on the vertical motions and loads of a containership in regular waves. J Ship Res 48(2):118-147

Fonseca N, Guedes Soares C (2005) Comparison between experimental and numerical results of the nonlinear vertical ship motions and loads on a containership in regular waves. Int Shipbuild Progr 52(1):57-89

Fonseca N, Pascoal R, Guedes Soares C, Clauss G, Schmittner C (2010) Numerical and experimental analysis of extreme wave induced vertical bending moments on a FPSO. Appl Ocean Res 32(4):374390

Guedes Soares C, Cherneva Z, Antão EM (2003) Characteristics of abnormal waves in North Sea storm sea states. Appl Ocean Res 25(6):337-344 
Guedes Soares C, Fonseca N, Pascoal R, Clauss GF, Schmittner CE, Hennig J (2006) Analysis of design wave loads on an FPSO accounting for abnormal waves. J Offsh Mech Arct Eng 128(3):241-247

Haver S, Karunakaran D (1998) Probabilistic description of crest heights of ocean waves. In: Proceedings of the 5th international workshop on wave hindcasting and forecasting, Jan 26-30. Melbourne, FL

Irvine M, Longo J, Stern F (2008) Pitch and heave tests and uncertainty assessment for a surface combatant in regular head waves. J Ship Res 52(2):146-163

Kharif C, Pelinovsky E (2003) Physical mechanisms of the rogue wave phenomenon, Eur J Mech.B/Fluids 22:603-634

Petrova PG, Arena F, Guedes Soares C (2011) Space-time evolution of random wave groups with high waves based on the quasideterminism theory. Ocean Eng 38:1640-1648

Rajendran S, Fonseca N, Guedes Soares C, Clauss GF, Klein M (2011) Time domain comparison with experiments for ship motions and structural loads on a container ship in abnormal waves. In: Proceedings of the 30th international conference on Offshore Mechanics and Arctic Engineering, ASME, pp 1-9
Salvesen N, Tuck EO, Faltinsen O (1970) Ship motions and sea loads. Trans SNAME 78:250-287

Slunyaev A, Pelinovsky E, Guedes Soares C (2005) Modeling freak waves from the North Sea. Appl Ocean Res 27:12-22

Veltcheva A, Guedes Soares C (2007) Analysis of abnormal wave records by the Hilbert Huang transform method. J Atmos Ocean Technol 24(9):1678-1689

Walker DAG, Taylor PH, Eatock Taylor R (2004) The shape of large surface waves on the open sea and the Draupner New Year wave. Appl Ocean Res 26:73-83

Watanabe I, Guedes Soares C (1999) Comparative study on the timedomain analysis of non-linear ship motions and loads. Mar Struct 12(3): 153-170

Watanabe I, Keno M, Sawada H (1989) Effects of bow flare shape on wave loads of a container ship. J Soc Naval Archit Jpn 166:259_ 266 